\title{
Knowing and Not Knowing about Fertility: Childless Women and Age-Related Fertility Decline
}

\author{
Lauren Jade Martin \\ Penn State Berks \\ ljm37@psu.edu
}

\begin{abstract}
Knowledge claims may play an essential role in reproductive decision-making, as individuals seek out, assess, reject, and use information about health and fertility gathered from numerous sources. This paper focuses specifically on childless women's self-perceptions of knowledge about infertility and age-related fertility decline. How knowledgeable do childless women perceive themselves to be about fertility and infertility in general, and from where they do they obtain this knowledge? Furthermore, how knowledgeable do childless women perceive themselves to be about their own fertility and ability to conceive, and to what do they attribute this knowledge? Data for this project was gathered through semi-structured interviews with 72 childless American women; the interviews were inductively and thematically coded using qualitative-analysis software. Childless women assessed their general knowledge of fertility as confident, self-doubting, or novices, and they claimed multiple sources as the basis of this knowledge, including formal education and training, media and popular culture, and family members and peers. When assessing knowledge about their own fecundity, the women tended to rely on two additional sources: biomedical diagnostics and embodied knowledge. Childless women's awareness of average statistics of age-related fertility decline did not necessarily translate to individual self-knowledge about their own bodies and fecundity. Because knowledge claims were based on multiple information sources given unequal weight, this raises questions about authoritative knowledge-that is, the knowledge that "counts" for women as they make decisions regarding their future childbearing.
\end{abstract}

Keywords: Life course; temporality; masculinity; sexual health; anti-aging medicine; Mexico

Anthropology \& Aging, Vol 42, No 1 (2021), pp. 30-48

ISSN 2374-2267 (online) DOI 10.5195/aa.2021.259

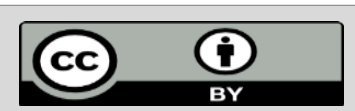

This work is licensed under a Creative Commons Attribution 4.0 International License.

This journal is published by the University Library System of the University of Pittsburgh as part of its

D-Scribe Digital Publishing Program, and is cosponsored by the University of Pittsburgh Press. 


\title{
Knowing, and Not Knowing about Fertility: Childless Women and Age-Related Fertility Decline
}

\author{
Lauren Jade Martin \\ Penn State Berks \\ ljm37@psu.edu
}

An hourglass in the form of an upturned baby bottle appears next to text that reads: "Advancing age decreases your ability to have children. While women and their partners must be the ones to decide when (and if) to have children, women in their twenties and thirties are most likely to conceive.... Your decisions now can impact your ability to conceive in the future. Get the Facts." This graphic, along with three others that focused on smoking, sexually transmitted infections, and weight, was part of an infertility-prevention campaign launched by the American Society for Reproductive Medicine (ASRM) in 2001 (American Society for Reproductive Medicine, n.d.). According to Michael R. Soules (2003), former president of ASRM, the campaign was initially small and targeted, involving public-service announcements on buses, 30-second radio spots, brochures, and a website. But the campaign soon caught the media's attention, which ran stories about its content. In particular, the media focused on the campaign's controversial images and messages as well as the backlash it was receiving from groups such as the National Organization for Women (Bute et al. 2010; Soules 2003).

More recent controversies have erupted across the world when government agencies or private corporations have enacted awareness campaigns about infertility, demographic decline, and delayed childbearing. These include a "Fertility Day" campaign to raise awareness of infertility and to encourage young women not to delay childbearing in Italy (Pianigiani 2016), viral "Do it for Denmark!" videos encouraging Danes to have sex to mitigate the country's low birth rate (Dearden 2016), and a Polish campaign urging citizens to "breed like rabbits" in their reproductive years (Associated Press 2017). South Korea, also facing low birth rates, courted controversy with a government website's publication of a map that used shaded colors to rank the regions within the country that had the greatest numbers of women of childbearing age. After public outcry, the map was immediately removed (Associated Press 2016). In each of these instances, public reaction was negative, with commentators, including working women, pointing out that the matter of population decline may be better resolved by addressing the structural problems that make it difficult to have and raise children; e.g., job security and childcare.

Moreover, several of these campaigns, including the ASRM campaign in the early 2000s, assumed that women are not knowledgeable about their bodies, fertility, or age-related reproductive decline. Without acknowledging what women already know about fecundity - as well as the structural constraints that frequently lead to delayed childbearing - the messaging in these campaigns came across as overly nationalistic, paternalistic, and insensitive. Women may also hear messaging from medical providers, the media, and peers about fertility, but they may not know how easy or difficult it will be for them personally to conceive if they have never attempted to get pregnant. Thus, the influence of knowledge 
claims may play an essential role in reproductive decision-making, as individuals seek out, assess, discard, and use information about health and fertility gathered from numerous sources.

This article is based on research conducted for a larger qualitative project on the reproductive decisionmaking of childless women in the United States. In this article, I focus specifically on two issues: (1) How knowledgeable participants perceive themselves to be about fertility and infertility in general, and from where they obtained this knowledge; and (2) how knowledgeable they perceive themselves to be about their own fertility and ability to conceive, and to what do they attribute this knowledge. Rather than measure or quantify childless women's knowledge about fertility and infertility, this paper engages with epistemological questions: what do childless women claim to know, how do they know what they know, and how do they value what they know? Central to this project is anthropologist Brigitte Jordan's (1993) concept of "authoritative knowledge," which posits that different knowledge systems exist simultaneously, but that only some types and sources of knowledge "count" and are seen as legitimate. As I discuss, women tend to rely upon and make various knowledge claims about fertility, and what they understand to be true or factual may not always be legitimated by medical providers, romantic partners, and others who are influential in their reproductive decision-making.

\section{Background}

Numerous researchers have studied the extent to which women and men are aware of age-related fertility decline-with sometimes contradictory results. For example, a telephone survey of 462 men and women aged 18 to 45 in Australia revealed significant knowledge gaps about age-related fertility decline and factors influencing fertility (Hammarberg et al. 2013), whereas a study of 3,000 childless women in Canada found high levels of awareness (over 90 percent) of age-related fertility decline (Daniluk, Koert, and Cheung 2012). In the United Kingdom, a small qualitative study of 18 women over age 35 found that many were unaware of factors (including age) that contribute to infertility risks (Cooke, Mills, and Lavender 2012). Research conducted both in the United States and internationally indicates that awareness of age-related fertility decline is correlated with health literacy and education (Bunting, Tsibulsky, and Boivin 2013; Gossett et al. 2013). However, studies of reproductive-health professionals indicate that even those who are highly educated and have medical training are not immune to underestimating infertility risks or overestimating the effectiveness of fertility treatments (Bonetti et al. 2008; García et al. 2017; Revelli et al. 2016).

Misconceptions about the effects of aging on fertility or the effectiveness of assisted reproductive technologies may result in individuals delaying childbearing (Balasch and Gratacós 2011; Mac Dougall, Beyene, and Nachtigall 2013; Maheshwari et al. 2008). In a study by health researchers Judith C. Daniluk, Emily Koert, and Anthony Cheung (2012), participants were very knowledgeable about age-related fertility decline but knew far less about the effectiveness of in-vitro fertilization (IVF). Studies on people's awareness of the effectiveness of assisted reproductive technologies are relevant to research on age-related fertility decline because they speak to the risks of assuming that fertility treatments can mitigate the risks of delaying childbearing (Hodes-Wertz et al. 2013; Johnson and Simon 2012; O'Brien et al. 2017).

However, measures of people's knowledge about aggregated statistics of age-related fertility decline and other infertility risk factors do not fully capture all of the individual, social, and financial variables that people may consider in their reproductive decision-making (Lavender et al. 2015; Hertz 2006; Martin 2017) nor do they capture the non-expert sources of reproductive knowledge gathered from peers, family members, or media and pop culture. For example, some researchers have studied the use 
of blogs and anonymous online forums as sources of knowledge for people trying to gather and share information about infertility and treatment (Harrison 2014; Omurtag et al. 2012; Speier 2011). Feminist philosopher Nancy Tuana (2006) argues that the women's health movement can be characterized as "an epistemological resistance movement" to reclaim, transform, and unleash knowledge about women's bodies. Activists gain and dispense knowledge and expertise about reproductive bodies and functions through performing vaginal self-exams (Murphy 2004), reading and sharing health manuals such as Our Bodies, Ourselves (Davis 2007a), and forming reproductive health collectives (Roberts, Ross, and Kuumba 2005).

The above examples from the women's health movement emphasize the importance of knowledge grounded in women's experiences, particularly their embodied experiences. According to sociologist Patricia Hill Collins (2000), the role of concrete experience in knowledge production and truth-telling is a kind of "wisdom" that lends credibility. Sociologist Dorothy Smith (1991) likewise emphasizes the role of experiential knowledge, which is also located in and through the body. Writing about women's subjectivity in standpoint epistemology, Smith describes the "woman knower" who "stands outside textually mediated discourse, in the actualities of her local and particular world. She exists in and as a body that is the body of a woman" $(1991,159)$. With this paper, I hope to contribute to this scholarship by highlighting the importance of knowledge construction, evaluation, and the use of meaning-making activities in reproduction, including utility in decision-making about the timing of childbearing, behaviors related to seeking medical help, and reliance on technology.

Anthropologist Brigitte Jordan (1993) describes the embodied knowledge of a laboring woman in her classic study of childbirth; here, the woman reads signs and signals from her own body, which inform her about, e.g., when to begin pushing. In medicalized childbirth, however, a woman's embodied knowledge usually exists simultaneously with competing knowledge claims that are more procedural, status-bound, and typically accepted as authoritative. According to Jordan, "In any particular social situation a multitude of ways of knowing exist, but some carry more weight than others. Some kinds of knowledge become discredited and devalued, while others become socially sanctioned, consequential, even 'official,' and are accepted as grounds for legitimate inference and action" $(1993,150)$. What is important is not just what women know about fertility and about their bodies, but how they know what they know, and how they make use of their knowledge.

\section{Methods}

This project primarily relies upon qualitative, semi-structured interviews conducted in two waves. Between 2012 and 2014, I conducted interviews with 72 childless women either in person (primarily in public places such as coffee shops and parks), by phone, or over Skype. In order to participate in this first wave of the study, participants needed to identify as a woman between the ages of 25 and 40, childless or not having given birth to any children, and residing in the United States. Initially, I recruited participants by word-of-mouth through my own social networks, and then through 'snowball sampling.' This meant that participants turned to their own social networks (both real and virtual) to inform friends and acquaintances about the study and, in some cases, they provided me with contact information so I could directly reach out to potential research participants. The logic for this chainreferral, nonprobability-sampling technique is that childless women in their twenties and thirties are likely to know others who also met the study's criteria.

To compensate for the limitation of a small nonprobability sample, I aimed to include a sample that was diverse in terms of race/ethnicity, age, relationship status, and sexual orientation (see Table 1). The 
sampling method and inclusion criteria resulted in an overrepresentation of both highly educated and queer-identified women. Participants were initially recruited from the Northeast and Mid-Atlantic regions of the United States, and the snowball-sampling process resulted in additional participants from the West, Midwest, and Southern regions. There was participation from women residing in urban, suburban, and rural areas of these regions. Participants were recruited and data was collected until both a diverse sample and data saturation were achieved (Morse 1995).

Initial interviews with participants included a number of topics related to reproductive intentions and desires, family histories, and work/family conflicts. Between 2017 and 2019, a follow-up study was conducted to track fertility outcomes (i.e., pregnancies and births) and changes in participants' desire for children. This second wave of data was collected from 56 participants, each of whom completed an electronic survey; a smaller subsample also participated in a second round of in-depth qualitative interviews. In both waves, each interview took approximately one hour, was audio-recorded, and was later professionally transcribed. All names included in this article are pseudonyms.

Interview transcripts were inductively and thematically coded using the qualitative-analysis software Atlas.ti. I used a process of open coding to generate general themes, and then used an iterative process that relied on axial coding to generate and relate categories and subcategories (Strauss and Corbin 1990). The majority of cases cited in this article draw upon the first wave of interviews, which included explicit questions about fertility knowledge and awareness. For this article, I specifically focus on the themes of knowledge about and awareness of women's health, fertility, infertility, and assisted reproductive technologies.

\begin{tabular}{|l|l|}
\hline Characteristics & $\mathrm{n}=72$ \\
\hline Mean Age & 32 \\
\hline Race/Ethnicity & \\
\hline$\bullet \quad$ White (not Hispanic) & $56(78 \%)$ \\
\hline$\bullet \quad$ Women of Color & $16(22 \%)$ \\
\hline Sexual Orientation & \\
\hline$\bullet \quad$ Heterosexual & $45(62.5 \%)$ \\
\hline$\bullet \quad$ Lesbian/ Bisexual/ Queer/ Other & $27(37.5 \%)$ \\
\hline Relationship Status & \\
\hline$\bullet \quad$ Single & $22(31 \%)$ \\
\hline$\bullet \quad$ Partnered/ married & $50(69 \%)$ \\
\hline Highest Level of Education & \\
\hline$\bullet \quad$ High school graduate or some college & $5(7 \%)$ \\
\hline$\bullet \quad$ Bachelor's degree & $22(30.5 \%)$ \\
\hline$\bullet \quad$ Master's degree & $27(37.5 \%)$ \\
\hline$\quad$ Doctoral or professional degree (JD, MD, or & $18(25 \%)$ \\
\hline$\quad$ PhD) & \\
\hline
\end{tabular}

Table 1. Sample characteristics of the interview participants

Although quantitative surveys offer a means to measure and quantify women's awareness of fertility, age-related fertility decline, the effectiveness of fertility treatments, and related topics, these are not the focus of this article. Rather than attempt to measure the amount or accuracy of participants' knowledge, the use of in-depth qualitative interviews allowed me to gain a deeper understanding of how women assess and make sense of their own level of knowledge. 
Women's self-assessments are important because public-awareness campaigns in various countries, including the United States, tend to presume that women lack education or knowledge about their infertility risks and age-related fertility decline. In this study, I aimed to assess childless women's perceptions of how much they already knew on this topic. I asked the study's participants specific questions about how knowledgeable they were about fertility, fertility decline, and infertility treatments; this included further probes about the relationship between aging and difficulty in conceiving. Here, I find it important to make a distinction between how women typically assess their own general knowledge of in/fertility-i.e., information such as when fertility begins to decline on average, the relative effectiveness of infertility treatments, and factors that contribute to infertility, such as aging-and their assessment of their own fertility, which refers to their personal ability to conceive and birth a child. As I describe below, even when strong assertions of knowledge were made in the general domain, this did not necessarily translate to knowledge about or action in the personal domain.

\section{From confidence to doubt: self-assessment of infertility awareness}

During the interviews, I asked participants how knowledgeable they were about fertility, infertility, and reproductive technologies, and they responded with a self-assessment. Participants' self-assessments were not necessarily a reflection of how much they knew, but rather how much they thought they knew. This did not appear to be a reflection of education or other social categories, as each category contained a diverse range of education levels, ages, racial backgrounds, and sexual orientations. During the coding process, I identified three general categories related to how much knowledge participants attributed to themselves, and I then used an iterative process to go back and tag relevant sections with one of the three categories. ${ }^{1}$ I refer to these three categories of knowledge assessment as confident informationseekers, self-doubters, and novices.

\section{Confident information-seekers}

'Confident information-seekers' is the term I apply to those women who strongly asserted their knowledge about fertility. This group comprises the largest category ( 29 women, or $40 \%$ of the total sample). Confident information-seekers include those who described themselves as being "above average" in their knowledge, or who used phrases such as "pretty knowledgeable" or even "extremely knowledgeable" about fertility. Two participants, unprompted by me, even used Likert scales to characterize their knowledge as 3 on a scale of 0 to 5 , and 7 on a scale of 1 to 10 . All of the women in this category described what they knew about the point at which women's fertility begins to decline on average, and about the ease or difficulty of getting pregnant.

In addition to feeling secure about how much they knew about fertility, this group also seems to be characterized by a desire to do research and acquire more information. As I discuss below, the women's knowledge came from a variety of sources, including from family members and books. Some women also explained to me why they had above-average knowledge about fertility. Within this group, some had actively sought out information or conducted research on their own because of an abstract interest in women's health issues. Others obtained their knowledge through work- or school-related training in subjects such as nursing, biology, genetics, and sexual health. This group also includes those who said that their desire to learn about fertility stemmed from their plans to conceive.

Both personal and professional interests often intertwined to bolster this knowledge-seeking. For example, Brooke, who was 34 during her initial interview, described how a job she once had at a women's health clinic fed her interest in the topic: 
My knowledge comes from two different places. One, personal interest. I'm just very interested in it. The second part is before I went back to school, I had a job where I worked in a women's health clinic. It was an administrative position. It was for seven OB-GYNs [obstetrician-gynecologists], and I spent my free time reading everything I could get my hands on. I filed lots of charts and, while I was filing them, I would, like, look at people's stuff. I talked to the medical assistants. I was just very curious. I always am about whatever job I do. That was one that particularly had my interest so I tried to learn as much as I could about ... fertility issues. It's been an interest that continues, especially since it has a political dimension. It's something that is interesting to me.

Similarly, Belinda (age 34), attributed both personal and professional interest to her knowledge about fertility. Belinda is a nurse who described herself as "pretty knowledgeable," but said that she "had researched [fertility] pretty well" even before training as a nurse. Her education to become a nurse only served to increase her knowledge: "As a nurse, I think I learned a whole lot more, so I would say that I am far above average on education for fertility."

\section{Self-doubters}

I categorize 22 of the women (30.5\%) in my sample as 'self-doubters'. Self-doubters include those who were quick to state that they were not "experts." Typical statements included: "Not an expert but not completely ignorant on the subject," and "I think I'm very knowledgeable, but I'm not an expert." In actuality, self-doubters may be quite knowledgeable about fertility but they were less confident about what they knew. For example, Wilma (age 38) went to nursing school to become a midwife, worked in a postpartum unit, and pursued a Ph.D. to research childbirth. To someone without training or experience in fertility or maternal health, Wilma would likely be considered very knowledgeable about women's health, but Wilma did not see herself this way. Instead, she described her knowledge about fertility as ". . . impressionistic. I don't know any actual figures. I mean, I know that your fertility drops off somewhat steeply, although that is debated, after 35. I guess it's debated how much it drops off." Like the confidential information-seekers, self-doubters may have sought out information to educate themselves about fertility, but they were more likely to acknowledge how much they still do not know.

\section{Novices}

I refer to the third and smallest group (12 women, or 17\%) as 'novices'. This term comes directly from a participant, Shante (age 35), who pithily used it to describe her lack of knowledge about fertility. Like others in this group, she stated that she did not know much at all about fertility; most of these participants were even less confident about their knowledge than the self-doubters. Again, even though they may actually be quite knowledgeable, when responding to questions about how much they knew about fertility, they characterized themselves as having "minimal" awareness or being "not too knowledgeable." In Shante's case, she was aware that age 35 is "the age where you need to start to get things on the ball if you're going to do it," and have increased risks. She had also received conflicting information from medical professionals about the relationship between age and fertility decline:

I had one doctor say, 'Women are getting pregnant a lot later. If you keep yourself in good health, in good shape, exercise, you do all those things, it's very possible. Don't stress. Don't worry about it.' Then I've had it from the perspective of textbook, pretty much. 'These are the times that you know risks are more prevalent. Make sure that you are careful, if you're thinking about it, maybe you should start to think about it.' I've had it from both ends. 
Such conflicting messages may contribute to Shante's sense that she lacks precise knowledge about fertility despite the fact that, by many measures, she was fairly knowledgeable about age-related fertility decline.

Some novices expressed embarrassment about what they perceived to be their lack of knowledge. Alex (age 31) felt that she should know more than she does, telling me that she was "not as knowledgeable as a women's studies major should be. It's slightly embarrassing." As with the self-doubters, novices may possess general knowledge about infertility or age-related fertility decline but, because they could not cite hard facts or statistics, they did not value their own knowledge. The category of 'novices' also included women for whom having children was not yet on their radar, or who were totally uninterested in ever having children.

\section{Sources of knowledge: how do women know what they know about infertility?}

As I suggested above, when describing how much knowledge they felt they had about fertility, some participants also made claims about their information sources. These include expert knowledge gained through education and training or received directly from medical providers, knowledge gleaned from media and popular culture, and information passed on to them by family members, friends, and acquaintances. As some historians and women's health scholars have articulated, the rise of procedurally- and technologically-based medical knowledge has often come at the expense of other knowledge sources, particularly in the realm of reproduction; this means that the expertise of, e.g., physicians supercedes the expertise of midwives (Ehrenreich and English 2010; Jordan 1993; Rothman 2000). Mothers, those seeking to become mothers, and anyone with the potential to one day become a biological mother are expected to seek out expert knowledge about pregnancy, childbirth, and childrearing in order to fulfill cultural expectations of motherhood and gendered subjectivity (Hays 1996; Waggoner 2017; Miller 2003; Rothman 2007).

Even if they did not necessarily describe themselves as "experts," the study's participants relied on education, training, and information they received from experts, particularly those in medical and scientific fields. Participants cited the technical or scholarly information they learned via attending classes or work/volunteer training in fields related to health and biology, including nursing, midwifery, acupuncture, and genetics. They also received general knowledge about fertility and age-related fertility decline directly from medical providers. This information was not necessarily based on individual women's biomedical profile or history, but rather the conveyance of generalized facts and statistics. Conversations were initiated by either the medical provider or the woman about such topics as birth control or the timing of pregnancy.

In addition to these forms of expert knowledge, the study's participants also cited two additional sources of information: the media, and familial and peer sharing. Due to patient mistrust, some individuals may act as "biological citizens," seeking out health information on their own; this may sometimes contradict or disavow medical authority in favor of their own agency (Rose and Novas 2005). Moreover, the internet and social media have facilitated the ability to seek out health-related information, including fertility-related information, from peers and other nonmedical sources (Nettleton, Burrows, and O'Malley 2005; Hardey 1999; Hammarberg et al. 2017). When asked how they know what they know about fertility, some participants described conducting research and selfeducation on their own. They sought out books about fertility and tried to track down information on the internet. Sometimes, they came across new information that challenged expert opinions about age and fertility. For example, several mentioned reading an article by psychologist Jean Twenge (2013) in 
The Atlantic Monthly; it made them question whether one's fertility really does steeply decline at age 35:

Marie (age 29): I've heard a lot [about fertility] but since reading The Atlantic article, maybe I don't know as much as I thought I knew. . . . The number-one thing that jumped out at me, which I think is what the article was sort of centered around, was that apparently a lot of this data that people cite about fertility declining was from populations from like 1670 to 1830 or something like that. I'm not a scientist, but I would like to dig into that a little bit more - like, what exactly were they looking at, like, how much could that be influenced by our different nutritional levels and, you know, we're a lot taller than we were then, and we live a lot longer.

Natalie (age 37): I recently read the article, I forget if it was from The Atlantic ... It's like this data that we have about women's decline in fertility is based on French women from the 18th century. ... So, I was, like, okay, that made me feel a little bit better. That's been the knowledge I've been working with, has been the, you know, once you hit 30 you're already starting to go down, and then past 35 is just a really quick slope into infertility.

Despite the idea of an age-related "fertility cliff" (Waldby 2019) that some women have absorbed - and that reproductive medicine still generally upholds (Practice Committee of the American Society for Reproductive Medicine 2014) - several of the study's participants were willing to push back against this narrative. For example, Lizzie (age 33) was a confident information-seeker who told me she knew "probably way more than most" about women's fertility. Describing herself as a "collector of knowledge," she described how she sought out and assessed internet sources:

The internet is a fountain of wealth if you dig though all the chat. You can actually find real good solid knowledge. I try to compare and contrast knowledge, so I'll go to Planned Parenthood, and then I'll go to an anti-abortion site. I figure if they agree on something, [then it's] probably good knowledge. That's how I collect my knowledge on the internet. ... I'm a little bit more thorough than most.

In addition to information from internet sources, Lizzie also relied on what she learned and "collected" from personal contacts; these include her mother who is a labor and delivery nurse, friends who have experienced pregnancy, and a human sexuality class she took in college.

As Lizzie's example indicates, in addition to online and media sources, individuals also seek out health information from their personal contacts; e.g., family members, friends, and work colleagues. Participants in this study relied upon stories they heard about others' ease with or difficulty in conceiving. As such, awareness of others' experiences with infertility and treatments seems to inform what they know about fertility, infertility risks, aging, and the existence and effectiveness of reproductive technologies. Sociologists Sheila R. Cotten and Sipi S. Gupta (2004) describe these personal sources as "local experts"; i.e., people who have experience with a medical condition and may appear to be a more approachable source for advice and health information than medical providers. In one location where I conducted in-person interviews, I spoke individually with three different women who all cited the same friend as a source of information. This person acted as a "local expert" in their shared social network because they had experienced infertility and were seeking fertility treatments. By conducting research and relying on stories from within their own social networks, combined with any information acquired from experts, Lizzie and other study participants displayed their "biological 
citizenship" (Rose and Novas 2005) and "epistemological resistance" (Tuana 2006) as they considered and assessed knowledge about fertility, age-related fertility decline, and fertility treatments.

\section{How do women know what they know about their own fertility?}

Knowing general facts and statistics about infertility or age-related fertility decline is different from having a sense about one's own ability to conceive. That is, a person might be familiar with 'common' (albeit contested) knowledge about fertility decline after age 35, but this general knowledge is not necessarily helpful for gauging at what age a specific person should begin trying to conceive, whether or when they should seek medical assistance, or if they have undiagnosed infertility. Therefore, in my interviews with this group of childless women, I also asked if they had any idea about their own fertility or their ability to conceive and carry a child. In the following section, I present several cases that illustrate the different sources and types of knowledge that women incorporate into their understandings of their own fertility. In addition to the sources of knowledge mentioned above (e.g., experts, media, and family/peers), two new sources of knowledge emerge: biomedical knowledge and embodied knowledge.

\section{Biomedical knowledge}

Reproductive endocrinologists and other physicians focusing on reproduction and fertility typically use a variety of tests to diagnosis and predict infertility in adult women (Practice Committee of the American Society for Reproductive Medicine 2015). These may include ovarian reserve testing, which measures the number and quality of eggs through hormone tests and ultrasound. A woman's access to such biomedical knowledge about fertility can be both empowering and confounding. In an ethnographic study of individuals who used ovarian reserve testing, anthropologist Moira Kyweluk's (2020) participants reported gaining a sense of control from learning more information about their likelihood of future conception. This was especially important for LGBTQ and single participants who would not otherwise meet medical criteria for infertility diagnoses. However, the results of fertility tests did not necessarily translate into Kyweluk's participants knowing what to do with this information, nor did the results contribute to their reproductive decision-making needs.

Several of the participants in my study also grappled with obtaining and acting upon biomedical knowledge about their fertility. Marta was 30 years old when I first interviewed her over the phone in 2014. Ambivalent about having children, she told me that she had been thinking a lot about her own "biological timeline" since turning 30. When I asked Marta how knowledgeable she felt about women's fertility as it related to aging, she replied that she was "pretty knowledgeable." Like the other participants who I refer to as 'confident information-seekers,' Marta assessed her own awareness about fertility as relatively high, in part because of the research she had sought out on her own.

In our conversation about children, fertility, and her own reproductive future, Marta several times brought up a book she had recently read, The Big Lie: Motherhood, Feminism, and the Reality of the Biological Clock (Selvaratnam 2014). This book happened to be on my own bookshelf, and I recalled that it had an image of -no surprise here-an hourglass on its cover. In this book, author Tanya Selvaratnam catalogs her own pursuit of motherhood while dealing with infertility, and she expresses anger that she and other women like her had not been given adequate information about age-related fertility decline. Selvaratnam advocates that women pursue this knowledge and become informed about "the reality of their biological clocks" $(2014,229)$. This advice is somewhat akin to the women's health activists who had previously advocated for women to take control and learn more about their bodies with speculums and mirrors (Murphy 2004; Davis 2007a). But Selvaratnam suggests very different means: instead of 
women relying on their own hands and embodied experiences through the use of 'do it yourself' methods, ovarian reserve testing relies upon medical expertise and technology.

This reliance on medical expertise ultimately proved to be a barrier for Marta in her quest for more selfknowledge. After reading Selvaratnam's book and seeing an episode of the sitcom "New Girl" about egg freezing, Marta decided to get a blood test and ultrasound in order to get a sense of her own fertility. "I think most women - unless they've been around people who can't have kids - just think they can get pregnant when they want to," said Marta. "Reading that book and seeing that now is the time to find out what I'm working with, so to speak, really inspired me to be armed with as much education about myself as possible so I can make educated decisions." Although she had not yet pursued diagnostic tests, Marta told me in her first interview that she had already visited a fertility clinic "just to open the dialogue." At the clinic, they explained the process of egg freezing, which she said turned her off: "It's ten days of injecting yourself with shots, and your body goes through all this crap it's not meant to be going through at that time. It was a little bit scary, but doing the blood test and the ultrasound are not scary, so I'll take those steps first."

Four years after our initial conversation, I interviewed Marta, who was then age 34, by phone. Because she had never tried to get pregnant, Marta told me that she still did not know whether or not she would have difficulty conceiving or need fertility treatments. The diagnostic tests that she had been so determined to take during her first interview had still not transpired. Again, Marta brought up The Big Lie and the feeling she had when reading it that she wanted to get as much information about her body as she could. A blood test and ultrasound were still on her agenda; however, Marta said that she recently asked her doctor about whether she could still take "one of those tests" to measure her fertility, and she was informed that her doctor would not administer it unless she had been trying to get pregnant without success.

So, to what end should attaining knowledge about one's body be pursued? In Marta's case, there was a contradiction between why Marta sought knowledge about her body, and what her doctor perceived to be an appropriate use of diagnostic tools. Even though Marta wanted to learn about her body and her fertility for her own knowledge-i.e., to help her make decisions about whether to pursue having children or to freeze her eggs - from her physician's point of view, measuring fertility should only be done while actively trying to conceive and in the direct pursuit of an infertility diagnosis. Thus, Marta could freely pursue general knowledge about the relationship between fertility and aging, but she lacked-and was denied-the tools to pursue personalized biomedical knowledge about her own ability to conceive.

Other than those women who were actively attempting to conceive, most participants in this study had not undergone ovarian reserve testing. One exception was Arie (age 37), who was determined to become a mother but worried about running out of time. She had already tested her FSH (follicle-stimulating hormone) and AMH (anti-Müllerian hormone) levels to gauge how easily she might conceive. She had had her FSH tested when she was 33 and then again shortly before being interviewed, along with two other hormone tests. Because her results were contradictory, she had scheduled an appointment with a fertility specialist. Arie was in somewhat of a bind, though, because she wanted to know definitively about the likelihood of having a biological child one day but she also worried about what she might learn:

Am I making a mistake by going to the doctor to face whatever they're going to tell me so then I have the knowledge, so I can't go on a date or go out with a guy and get to a 
point where, I mean, at some point if I find out I can't have kids, I'm going have to tell them. ... In future relationships, would I be better off just not knowing so that I could go into a relationship and then [we] figure it out together?

In a follow-up email to me, Arie disclosed that the fertility specialist had informed her that she still had viable eggs, but a low reserve of them; this meant that she should act quickly to either freeze her eggs or inseminate with a sperm donor.

\section{Knowledge obtained from family and friends}

Assessing one's own fertility can take the form of relying upon biomedical knowledge (as Marta and Arie did), undergoing diagnostic testing for evidence of fecundity, or receiving information from fertility experts about the probable chances of conceiving or carrying a pregnancy to term based on particular health conditions. However, acquiring biomedical knowledge from these sources may make one reliant on medical gatekeepers. Thus, just as women like Lizzie gained general knowledge about fertility from "local experts" within their own social networks (Cotten and Gupta 2004), some participants in my study also relied on stories told by family members, friends, and acquaintances in order to self-assess their own fertility.

In some cases, discussions between friends may contradict medically-informed information about fertility. For example, Ruthie (age 33) told me that she was pretty sure she wants to have a child. She belonged to the group I describe as 'self-doubters.' Although she said she had "a decent amount of knowledge" about women's fertility -in part because she grew up in a family with "fairly high access to medical information" - she qualified how much she actually knew: "I . . . feel like things are changing so fast in the field of fertility and reproductive health that I'm not sure that I actually feel like I'm a super-knowledgeable source."

Within Ruthie's circle of friends, people talked about having kids on their own timelines, without much worry about the effect of aging on infertility. But when Ruthie attended a training session for volunteer doulas (i.e., people who provide physical and emotional support during childbirth), the topic of an "optimal age" to conceive came up, and Ruthie characterized it as contradicting how her friends thought about the relationship between age and reproduction. "I feel like I just had this moment where it struck me where it was just like hearing someone say, 'Oh yeah, it's optimal to have kids between 25 and 35,' and just kind of being thrown off because that's not a fact that's flung around in most of the circle that I'm in, and then kind of having a moment of, like, 'Oh my God, I'm almost 35.'” The significance of age 35 (or age 30 in Marta's case) in relation to fertility has larger cultural resonance in the United States and other Western nations, as this age is frequently invoked as a milestone in the life course. Specifically, it is the age at which pregnant people are labelled "geriatric" because they have a greater risk for having children with genetic conditions, and it is the age at which egg quality is assumed to begin its rapid descent (Martin 2017; Waldby 2019).

This medically informed concern about age-related fertility decline was reinforced by Ruthie's mother, a physician who suggested that she and her partner freeze their sperm and eggs; she also warned Ruthie that she had "read that babies born to mothers [over 35] are higher risk." These conversations about aging seemed to impact Ruthie's feeling that she should have a child "within the next year and a half like, I need to just make that a priority and get it done."

Family lore also informed some women's self-assessments of their own fertility. This meant that, in order to gauge their own fertility, women often considered their family members' ease with or difficulty 
in conceiving, their histories of miscarriage, and their use of reproductive technologies. For example:

Ingrid (age 27): You know, I don't really know if I'm fertile or not. I take birth control because I just don't want to have kids. Historically in my family, my mom got pregnant late in life, and she didn't need a lot of help, and my grandmother had twins without knowing it at a time when they were really poor. . . There aren't a lot of fertility problems in my family. My extended family, it seems like everyone has tons of kids.

Daphne (age 32): My cousin was actually unable to have kids. It hasn't been a problem with anybody else in the family, but I tend to take after my aunt and my cousin more.

... We are actually pretty similar. I have always wondered kind of about that.

Here, Daphne claimed that her physical resemblance to some family members in terms of "body type and features and things like that" made her think that she may also share with them a genetic propensity towards problems with fertility.

\section{Embodied knowledge}

Another important source for women's self-assessment was their embodied knowledge. According to sociologist Kathy Davis $(2007 a, 13)$ women are epistemic agents whose bodily experiences are "never a simple reflection of reality," but they can "still be used as a starting point for understanding what it means to live in a particular body, at a specific moment in time, or in a particular social location", and that this knowledge "can be juxtaposed with other forms of knowledge." In my study, many of the women intuited information about their fertility based on their own bodies, experiences, and histories, but this knowledge was not necessarily isolated from information they received from experts, family members or peers, or through their own research. Instead, they incorporated it with their own sense of what was happening to or within their bodies. As epidemiologist Abby Lippman $(1999,259)$ writes in her study of prenatal diagnosis, "embodied knowledge resulted from various transformative, interpretive, and integrative processes in which women engaged to refashion 'received' biomedical information, taking ownership of it and weaving it together with their own experiences and understandings and with 'inside' information, their feelings and beliefs." The "inside information" to which the childless women in my study referred included prior pregnancies, lack of unintended pregnancy after unprotected sex, their history of birth-control use, the duration and frequency of their menstrual cycles, experiences with polycystic ovary syndrome (PCOS) or other health conditions, or just "knowing" - i.e., having an internal sense about their probability of conceiving.

Like Marta, Ruthie's actual fertility remained unknown to her except for the fact that she had never had an unplanned pregnancy in over a decade of sexual activity. Since she had not yet intentionally tried to conceive, she worried about how difficult it would be to become pregnant. In fact, the thought of not being able to get pregnant was so scary to her, Ruthie said that she was almost afraid to even try. Despite these concerns, Ruthie had not (as Marta and Arie had done) embarked on a quest for information about her own ability to conceive.

Never experiencing pregnancy, even an unplanned one, was significant for a number of participants, including Jeannie (age 28). She told me that she wants to have children someday but did not know how easy or difficult it would be to get pregnant:

This is kind of embarrassing. Because I really don't know anything about anything, but it's definitely crossed my mind. I've been on birth control since I was 14 because I would 
get my period every two weeks and pass out. I wasn't, like, sexually active at 14 . I'm, like, kind of worried about what my body's going to do when I go off [birth control]. I don't know. Are there long-term effects to taking birth control for that long? I have no idea. I've made up scenarios in my head that are terrible. I should probably just research it.

In this case, Jeannie felt that she lacked the kind of embodied knowledge that would help her assess her fertility. Because she had never tried to get pregnant and had been on birth control continuously since she was a teenager, she believed that she could not know her odds for becoming pregnant. Moreover, she did not know "what [her] body's going to do" if she stopped using birth control.

Whereas Jeannie admitted that she did not know much about her own fertility, other women in the study expressed a "sense" or intuition about what their bodies were capable of. For example, Gwendolyn (age 35) said that she does not want children but also does not think she would get pregnant easily.

Gwendolyn: I've never tried. And I've never had any sense - well, I have an intuitive sense that I would not have an easy time, but that's just my psychology rather than anything. But intuitively, I don't think it would be very easy for me.

Author: Do you have any idea why it might be difficult?

Gwendolyn: Well, I have health issues. I'm a very healthy person, and I exercise and eat well and whatever, but I just feel that my body has always had a harder time doing things than most people. I feel that that would be one more - you know, if I really wanted to have kids, I feel like it would give me a hard time just because it's always given me a hard time.

Similar to Jeannie, Gwendolyn had never attempted to get pregnant, yet she relied upon her 'gut feelings' and intuition to make what she considered to be an educated guess about her ability to conceive. In Gwendolyn's case, her past experiences with her body having "a harder time doing things than most people" influenced her assessment of her own fertility.

\section{Combining knowledge sources}

Some women in the study used a combination of different types of knowledge to assess their ability to conceive. For example, at the time of her initial interview, Jennifer (age 33) was actively attempting to get pregnant yet had so far been unsuccessful. I categorized her as a 'self-doubter' because, even though she described herself as becoming more knowledgeable about women's fertility, she said, "I probably would embarrass myself if given a quiz. I do have the book Taking Charge of Your Fertility." As far as assessing her own fertility, Jennifer mentioned her mother, who had experienced infertility and a series of miscarriages but then got unexpectedly pregnant with Jennifer years after adopting a child. Jennifer also knew how "emotionally painful" infertility can be, based on a friend's experience with IVF after not being able to conceive. "It's tough," Jennifer said. "The desperation to have a child and then kind of not being able to."

Moreover, Jennifer had access to some biomedical knowledge about her own fertility from physicians: "I have one ovary because I had an ovarian torsion a few years ago so I'm working with half. I had an IUD [intrauterine device], and I had it removed, and the surgeon said, 'You've got some fibroids. That 
can affect fertility. I wouldn't suggest waiting. I would just go to the fertility specialist right now.'” Despite being urged to seek fertility treatment, Jennifer was hesitant. She was too busy to make time for an appointment, and she also worried about the possibility of having triplets if she went through IVF. Recalling her friend's "unpleasant" and unsuccessful experience with IVF, Jennifer said, "One of the reasons I haven't gone [to a specialist] was: what if they tell me I can't do it at all? That's obviously a concern but everyone has to bite the bullet."

By not seeing a fertility specialist, Jennifer managed to shield herself from knowledge that she potentially did not want to hear; this echoed the fears that Marta and Arie expressed in relation to learning unwanted information. In the meantime, Jennifer and her husband were trying to conceive without medical intervention. Instead of seeking out biomedical treatment, Jennifer wanted to be "more in charge of my fertility" by using ovulation test strips, which enabled her to rely upon embodied knowledge about her body and its natural cycles. Another source of embodied knowledge was an unplanned pregnancy that she terminated early in her relationship. Like other women in the study, Jennifer hoped that previous pregnancies-even if they were unplanned and terminated - were at least evidence that conception would be possible in the future. Through their evaluation, use, and/or rejection of different types and sources of knowledge, Jennifer and the other women in the study thus acted as epistemic agents, literally "taking charge of their fertility," as so many told me they were eager to do.

\section{Discussion and conclusion}

In my study, the women claimed to possess different degrees of knowledge about fertility, regardless of their educational background or other social characteristics. This led me to categorise them as confident information-seekers, self-doubters, or novices. However, their self-assessment did not necessarily correlate with how much they actually knew, or how accurate their information was. Thus, the women's awareness of the relationship between aging and fertility decline did not necessarily translate to their individual self-knowledge about their own bodies and fecundity. Furthermore, certain knowledge claims were based on multiple information sources. Whereas some women relied on their formal education or diagnoses from physicians, others counted on their family history, signs they read from their own bodies and bodily processes, and even upon intuition. This raises many questions about authoritative knowledge-i.e., the knowledge that "counts" for women as they make decisions regarding future childbearing (Jordan 1993).

In some cases, "objective" medical or scientific claims from medical providers may provide women with useful information that helps them engage in reproductive decision-making, but this is only useful when they are given access to the knowledge they seek about their bodies (Kyweluk 2020). Expertderived knowledge may also be devalued or rejected by those women who research and seek out information on their own from sources such as social media or peers, or other non-medical sources, and who thereby enact their "biological citizenship" (Rose and Novas 2005; Hammarberg et al. 2017). Some women may also display epistemological resistance (Tuana 2006) or exert epistemic agency (Davis $2007 \mathrm{~b}$ ) when they take their own experiential and embodied knowledge as the most authoritative source to guide them in their reproductive decision-making.

Public-health campaigns often attempt to influence women's childbearing behavior in a normative fashion, yet it is debatable whether they serve as authoritative sources of information that play a role in individual reproductive decision-making. In order to increase awareness about fertility and/or agerelated fertility decline, it is important to acknowledge the multiple sources of information that women typically seek out and rely on; teaching individuals how to locate and evaluate health information may 
be a more sensible public-health goal (Demner-Fushman, Mrabet, and Ben Abacha 2020). Furthermore, while public-awareness campaigns aim to increase women's general knowledge about potential risks to their fertility, including aging, what these campaigns cannot do is increase women's individual knowledge about their own body's ability to conceive. Many participants in my study displayed an understanding about the differences between aggregated and statistical data (i.e., when women on average experience fertility decline) and individual circumstances (i.e., how one's body, experiences, and family history impact one's ability to conceive). My study suggests that, when it comes to assessing their own fertility, some women may not weigh average statistics about age-related fertility decline and other infertility risks as strongly as individual biomedical diagnostics, family histories, and embodied knowledge.

Despite the assumptions embedded in many public-health campaigns-i.e., that women are unaware of or uneducated about the potential risks of aging on their fertility-my study indicates that childless women are actually quite knowledgeable. They may doubt how much they know, or defer to the expertise of physicians and scientists, but nearly every woman I interviewed knew that, as we age, it becomes more difficult to conceive. Images of hourglasses and clocks that evoke panic or anxiety are used to encourage women to not delay childbearing - but, as I have suggested, such imagery is both trite and unnecessary. By studying where childless women are most likely to receive information-and which sources they are most likely to consider authoritative and meaningful - we can better understand the epistemic context in which infertility awareness campaigns operate. We may also apply this to other domains within the sociology and anthropology of aging beyond fertility and reproduction. Publichealth campaigns that attempt to raise awareness about, urge screening for, or nudge other actions regarding conditions or social problems associated with aging (e.g., breast and prostate cancer, cognitive decline, or social isolation) also occur within an epistemic context. It would be worthwhile for qualitative researchers to assess the existing knowledge claims and authoritative knowledge sources of those who, because of the aging process, have been labeled as "at risk" for certain conditions or social problems.

\section{Notes}

1. Nine participants (12.5\%) did not include much self-assessment of fertility knowledge during their interviews and were thereby not categorized.

\section{References}

American Society for Reproductive Medicine. n.d. "Protect Your Fertility." Get the Facts PSA Images. Accessed November 5, 2019. https://www.asrm.org/resources/patient-resources/pyfdocuments/protect-your-fertility/.

Associated Press. 2016. "South Korea Shuts Website Mapping Women of Childbearing Age." SF Gate, December 30, 2016. https://www.sfgate.com/world/article/South-Korea-shuts-websitemapping-women-of-10827268.php.

Associated Press. 2017. "Breed like Rabbits and Reverse Population Decline, Poles Urged." The Guardian, November 9, 2017. https://www.theguardian.com/world/2017/nov/09/breed-likerabbits-and-reverse-population-decline-poles-urged.

Balasch, Juan, and Eduard Gratacós. 2011. "Delayed Childbearing: Effects on Fertility and the Outcome of Pregnancy." Fetal Diagnosis and Therapy 29 (4): 263-73. https://doi.org/10.1159/000323142. 
Bonetti, T. C. S., R. M. M. Melamed, D. P. A. F. Braga, C. Madaschi, A. Iaconelli Jr, F. F. Pasqualotto, and E. Borges Jr. 2008. "Assisted Reproduction Professionals' Awareness and Attitudes towards Their Own IVF Cycles." Human Fertility 11 (4): 254-58. https://doi.org/10.1080/14647270802245885.

Bunting, Laura, Ivan Tsibulsky, and Jacky Boivin. 2013. "Fertility Knowledge and Beliefs about Fertility Treatment: Findings from the International Fertility Decision-Making Study." Human Reproduction 28 (2): 385-97. https://doi.org/10.1093/humrep/des402.

Bute, Jennifer J., Lynn M. Harter, Erika L. Kirby, and Marie Thompson. 2010. "Politicizing Personal Choices: The Storying of Age-Related Infertility in Public Discourses." In Contemplating Maternity in an Era of Choice: Explorations into Discourses of Reproduction. Edited by Sara Hayden and Lynn O'Brien Hallstein, 49-69. Lanham, MD: Lexington Books.

Collins, Patricia Hill. 2000. Black Feminist Thought: Knowledge, Consciousness, and the Politics of Empowerment. New York: Routledge.

Cotten, Shelia R, and Sipi S Gupta. 2004. "Characteristics of Online and Offline Health Information Seekers and Factors That Discriminate between Them." Social Science \& Medicine 59 (9): 17951806. https://doi.org/10.1016/j.socscimed.2004.02.020.

Daniluk, Judith C., Emily Koert, and Anthony Cheung. 2012. "Childless Women's Knowledge of Fertility and Assisted Human Reproduction: Identifying the Gaps." Fertility and Sterility 97 (2): 420-26. https://doi.org/10.1016/j.fertnstert.2011.11.046.

Davis, Kathy. 2007a. The Making of Our Bodies, Ourselves: How Feminism Travels across Borders. Durham \& London: Duke University Press.

----. 2007b. "Reclaiming Women's Bodies: Colonialist Trope or Critical Epistemology?1." The Sociological Review 55 (s1): 50-64. https://doi.org/10.1111/j.1467-954X.2007.00692.x.

Dearden, Lizzie. 2016. “Denmark's 'Do It Forever' Video Campaign Encourages People to Have Children to Get Discounted Holidays." Independent UK, November 21, 2016. https://www.independent.co.uk/news/world/europe/denmark-do-it-for-mum-forever-newspies-video-campaign-birth-rate-discounted-holidays-population-a7429221.html

Demner-Fushman, Dina, Yassine Mrabet, and Asma Ben Abacha. 2020. “Consumer Health Information and Question Answering: Helping Consumers Find Answers to Their Health-Related Information Needs." Journal of the American Medical Informatics Association 27 (2): 194-201. https://doi.org/10.1093/jamia/ocz152.

Ehrenreich, Barbara, and D. English. 2010. Witches, Midwives, and Nurses: A History of Women Healers. 2nd ed. New York: The Feminist Press at CUNY.

García, Désirée, Rita Vassena, Andrés Prat, and Valérie Vernaeve. 2017. "Poor Knowledge of AgeRelated Fertility Decline and Assisted Reproduction among Healthcare Professionals." Reproductive BioMedicine Online 34 (1): 32-37. https://doi.org/10.1016/j.rbmo.2016.09.013.

Gossett, Dana R, Shweta Bhatt, Stacy C Bailey, and Shweta Nayak. 2013. “What Do Healthy Women Know About the Consequences of Delayed Childbearing?" Journal of Health Communication 18: 118-28. https://doi.org/10.1080/10810730.2013.825677.

Hammarberg, Karin, Rebecca Zosel, Caroline Comoy, Sarah Robertson, Carol Holden, Mandy Deeks, and Louise Johnson. 2017. "Fertility-Related Knowledge and Information-Seeking Behaviour 
among People of Reproductive Age: A Qualitative Study." Human Fertility 20 (2): 88-95. https://doi.org/10.1080/14647273.2016.1245447.

Hardey, Michael. 1999. “Doctor in the House: The Internet as a Source of Lay Health Knowledge and the Challenge to Expertise." Sociology of Health \& Illness 21 (6): 820-32.

Harrison, Katherine. 2014. “Online Negotiations of Infertility: Knowledge Production in (in)Fertility Blogs." Convergence 20 (3): 337-51. https://doi.org/10.1177/1354856514531400.

Hays, Sharon. 1996. The Cultural Contradictions of Motherhood. New Haven: Yale University Press.

Hertz, Rosanna. 2006. Single by Chance, Mothers by Choice. New York: Oxford University Press.

Hodes-Wertz, Brooke, Sarah Druckenmiller, Meghan Smith, and Nicole Noyes. 2013. "What Do Reproductive-Age Women Who Undergo Oocyte Cryopreservation Think about the Process as a Means to Preserve Fertility?" Fertility and Sterility 100 (5): 1343-1349.e2. https://doi.org/10.1016/j.fertnstert.2013.07.201.

Johnson, Katherine M., and Richard M. Simon. 2012. “Women's Attitudes Toward Biomedical Technology for Infertility: The Case for Technological Salience." Gender \& Society 26 (2): 26189. https://doi.org/10.1177/0891243211434615.

Jordan, Brigitte. 1993. Birth in Four Cultures: A Crosscultural Investigation of Childbirth in Yucatan, Holland, Sweden, and the United States (4th ed., revised and expanded by R. Davis-Floyd). Long Grove, IL: Waveland Press.

Kyweluk, Moira A. 2020. "Quantifying Fertility? Direct-to-Consumer Ovarian Reserve Testing and the New (in)Fertility Pipeline." Social Science \& Medicine; Oxford 245 (January): 1. http://dx.doi.org.ezaccess.libraries.psu.edu/10.1016/j.socscimed.2019.112697.

Lavender, Tina, Janette Logan, Alison Cooke, Rebecca Lavender, and Tracey A. Mills. 2015. “'Nature Makes You Blind to the Risks': An Exploration of Womens' Views Surrounding Decisions on the Timing of Childbearing in Contemporary Society." Sexual and Reproductive Healthcare 6 (3): 157-63. https://doi.org/10.1016/j.srhc.2015.04.006.

Lippman, Abby. 1999. "Embodied Knowledge and Making Sense of Prenatal Diagnosis." Journal of Genetic Counseling 8 (5): 255-74. https://doi.org/10.1023/A:1022901131305.

Mac Dougall, K., Y. Beyene, and R. D. Nachtigall. 2013. "Age Shock: Misperceptions of the Impact of Age on Fertility before and after IVF in Women Who Conceived after Age 40." Human Reproduction 28 (2): 350-56. https://doi.org/10.1093/humrep/des409.

Maheshwari, A., M. Porter, A. Shetty, and S. Bhattacharya. 2008. “Women's Awareness and Perceptions of Delay in Childbearing." Fertility and Sterility 90 (4): 1036-42. https://doi.org/10.1016/j.fertnstert.2007.07.1338.

Martin, Lauren Jade. 2017. "Pushing for the Perfect Time: Social and Biological Fertility." Women's Studies International Forum 62 (May): 91-98. https://doi.org/10.1016/j.wsif.2017.04.004.

Miller, Tina. 2003. "Shifting Perceptions of Expert Knowledge: Transition to Motherhood." Human Fertility 6 (3): 142-46. https://doi.org/10.1080/1464770312331369413.

Morse, Janice M. 1995. "The Significance of Saturation." Qualitative Health Research 5 (2): 147-49. https://doi.org/10.1177/104973239500500201. 
Murphy, Michelle. 2004. "Immodest Witnessing: The Epistemology of Vaginal Self-Examination in the U.S. Feminist Self-Help Movement." Feminist Studies 30 (1): 115-47. www.jstor.org/stable/3178561

Nettleton, Sarah, Roger Burrows, and Lisa O'Malley. 2005. “The Mundane Realities of the Everyday Lay Use of the Internet for Health, and Their Consequences for Media Convergence." Sociology of Health \& Illness 27 (7): 972-92. https://doi.org/10.1111/j.1467-9566.2005.00466.x.

O’Brien, Yvonne, Fiona Martyn, Louise E. Glover, and Mary B. Wingfield. 2017. “What Women Want? A Scoping Survey on Women's Knowledge, Attitudes and Behaviours towards Ovarian Reserve Testing and Egg Freezing." European Journal of Obstetrics \& Gynecology and Reproductive Biology 217 (October): 71-76. https://doi.org/10.1016/j.ejogrb.2017.08.024.

Omurtag, Kenan, Patricia T. Jimenez, Valerie Ratts, Randall Odem, and Amber R. Cooper. 2012. "The ART of Social Networking: How SART Member Clinics Are Connecting with Patients Online." Fertility and Sterility 97 (1): 88-94. https://doi.org/10.1016/j.fertnstert.2011.10.001.

Pianigiani, Gaia. 2016. “Italy's 'Fertility Day' Call to Make Babies Arouses Anger, Not Ardor." New York Times, September 13, 2016. https://www.nytimes.com/2016/09/14/world/europe/italybirths-fertility-europe.html? $\mathrm{r}=0$

Practice Committee of the American Society for Reproductive Medicine. 2014. "Female Age-Related Fertility Decline." Fertility and Sterility $101 \quad$ (3): 633-34. https://doi.org/10.1016/j.fertnstert.2013.12.032.

Practice Committee of the American Society for Reproductive Medicine. 2015. "Diagnostic Evaluation of the Infertile Female: A Committee Opinion." Fertility and Sterility 103 (6): e44-50. https://doi.org/10.1016/j.fertnstert.2015.03.019.

Revelli, Alberto, Alessandra Razzano, Luisa Delle Piane, Simona Casano, and Chiara Benedetto. 2016. "Awareness of the Effects of Postponing Motherhood among Hospital Gynecologists: Is Their Knowledge Sufficient to Offer Appropriate Help to Patients?" Journal of Assisted Reproduction and Genetics 33 (2): 215-20. https://doi.org/10.1007/s10815-015-0640-x.

Roberts, Lynn, Loretta Ross, and M. Bahati Kuumba. 2005. “The Reproductive Health and Sexual Rights of Women of Color: Still Building a Movement." NWSA Journal 17 (1): 93-98. www.jstor.org/stable/4317103.

Rose, Nikolas, and Carlos Novas. 2005. "Biological Citizenship." In Global Assemblages: Technology, Politics, and Ethics as Anthropological Problems. Edited by Aihwa Ong and Stephen J. Collier, 439-63. Malden, MA: Blackwell Publishing.

Rothman, Barbara Katz. 2000. Recreating Motherhood: Ideology and Technology in a Patriarchal Society. New Brunswick (N.J.): Rutgers University Press.

Rothman, Barbara Katz. 2007. “Laboring Now: Current Cultural Constructions of Pregnancy, Birth, and Mothering." In Laboring On: Birth in Transition in the United States. Edited by Wendy Simonds, Barbara Katz Rothman, and Bari Meltzer Norman. New York and London: Routledge. https://doi.org/10.4324/9780203944554-10.

Selvaratnam, Tanya. 2014. The Big Lie: Motherhood, Feminism, and the Reality of the Biological Clock. Amherst, NY: Prometheus Books.

Smith, Dorothy E. 1991. “Writing Women's Experience into Social Science.” Feminism \& Psychology 1 (1): 155-69. https://doi.org/10.1177/0959353591011019. 
Soules, Michael R. 2003. "The Story behind the American Society for Reproductive Medicine's Prevention of Infertility Campaign." Fertility and Sterility 80 (2): 295-99. https://doi.org/10.1016/S0015-0282(03)00667-8.

Speier, Amy R. 2011. "Brokers, Consumers and the Internet: How North American Consumers Navigate Their Infertility Journeys." Reproductive BioMedicine Online (Reproductive Healthcare Limited) 23 (5): 592-99. https://doi.org/10.1016/j.rbmo.2011.07.005.

Strauss, Anselm L., and Juliet M. Corbin. 1990. Basics of Qualitative Research: Grounded Theory Procedures and Techniques. Newbury Park: Sage Publications, Inc.

Tuana, Nancy. 2006. “The Speculum of Ignorance: The Women's Health Movement and Epistemologies of Ignorance." Hypatia 21 (3): 1-19. https://doi.org/10.1111/j.1527-2001.2006.tb01110.x.

Twenge, Jean. 2013. "How Long Can You Wait to Have a Baby?" The Atlantic, no. July/August: 54-60. https://www.theatlantic.com/magazine/archive/2013/07/how-long-can-you-wait-to-have-ababy/309374/.

Waggoner, Miranda R. 2017. The Zero Trimester: Pre-Pregnancy Care and the Politics of Reproductive Risk. Berkeley, CA: University of California Press.

Waldby, Catherine. 2019. The Oocyte Economy: The Changing Meaning of Human Eggs. Durham: Duke University Press. https://www.dukeupress.edu/the-oocyte-economy. 